\title{
O rap e o funk na socialização da juventude
}

JuarezDayrell

Universidade Federal de Minas Gerais

\section{Resumo}

0 texto se propõe a discutir a importância dos grupos musicais juvenis nos processos de socialização vivenciados por jovens pobres na periferia de Belo Horizonte, problematizando o peso e o significado de ser membro de um grupo musical no conjunto da vida de cada um. Tem como foco os integrantes de três grupos de rape três duplas de funk procurando analisar as suas experiências culturais e o sentido que tais práticas adquirem no conjunto dos processos sociais que os constituem como sujeitos. Significa compreender como eles elaboram as suas vivências em torno do estilo, e os significados que atribuem a elas, no contexto social onde se inserem como jovens pobres.

A discussão aponta que os jovens rappers e funkeirosencontram poucos espaços nas instituições do mundo adulto para construir referências e valores por meio dos quais possam se construir como sujeitos. Os estilos rap e funkassumem uma centralidade na vida desses jovens por intermédio das formas de sociabilidade que constroem, da música que criam, e dos eventos culturais que promovem.

Esses estilos possibilitaram e vem possibilitando a esses jovens práticas, relações e símbolos por meio dos quais criam espaços próprios, significando uma referência na elaboração e vivência da sua condição juvenil, além de proporcionar a construção de uma auto-estima e identidades positivas.

\section{Palavras-chave}

Juventude - Socialização - Cultura juvenil - Sociabilidade.
Correspondência:

Juarez Dayrell

Rua Dores do Indaiá, 104/301

31010-360-Belo Horizonte - MG

E-mail:juarez@fae.ufmg.br 


\title{
The rap and the funk in the socialization of youngsters
}

JuarezDayrell

Universidade Federal de Minas Gerais

\begin{abstract}
The text proposes to discuss the importance of youngster music bands in the socialization processes experienced by poor youngsters from the outskirts of Belo Horizonte, problematizing the weight and meaning of belonging to a music band in the life of each one of them. The article focuses on the members of three rap bands and three funk duos, attempting to analyze their cultural experiences and the meaning that those practices acquire within the social processes that constitute them as subjects. That entails understanding how they elaborate on their experiences related with their music style and the meanings their attribute to it in their social context of poor youngsters.

The discussion points out that young rappers and funkers find few spaces in the institutions of the adult world where they can build up references and values through which they could constitute themselves as subjects. The rap and funk styles take on a central place in the lives of these youngsters by means of the forms of sociability that those styles build, the music they create, and the cultural events they promote. Those styles have made possible to those youngsters practices, relations, and symbols through which they create their own spaces, representing a reference in the elaboration and experience of their situation as youngsters, apart from allowing the construction of positive identities and self-esteem.
\end{abstract}

\section{Keywords}

Youth - Socialization - Youth culture - Sociability.

\footnotetext{
Correspondence:
} Juarez Dayrell

Rua Dores do Indaiá, 104/301 31010-360-Belo Horizonte - MG E-mail:juarez@fae.ufmg.br 
Nos últimos anos, e de forma cada vez mais intensa, podemos observar que os jovens vêm lançando mão da dimensão simbólica como a principal e mais visível forma de comunicação, expressa nos comportamentos e atitudes pelos quais se posicionam diante de si mesmos e da sociedade. É possível constatar esse fenômeno nas ruas, nas escolas ou nos espaços de agregação juvenil, onde os jovens se reúnem em torno de diferentes expressões culturais, como a música, a dança, o teatro, entre outras, e tornam visíveis, através do corpo, das roupas e de comportamentos próprios, as diferentes formas de se expressar e de se colocar diante do mundo.

0 mundo da cultura aparece como um espaço privilegiado de práticas, representações, símbolos e rituais no qual os jovens buscam demarcar uma identidade juvenil. Longe dos olhares dos pais, professores ou patrões, assumem um papel de protagonistas, atuando de alguma forma sobre o seu meio, construindo um determinado olhar sobre si mesmos e sobre o mundo que os cerca. Nesse contexto, a música é a atividade que mais os envolve e os mobiliza. Muitos deles deixam de ser simples fruidores e passam também a ser produtores, formando grupos musicais das mais diversas tendências, compondo, apresentando-se em festas e eventos, criando novas formas de mobilizar os recursos culturais da sociedade atual além da lógica estreita do mercado.

Esse processo não está presente apenas entre os jovens de classe média. Nas periferias constatamos uma efervescência cultural protagonizada por parcelas dos setores juvenis. Ao contrário da imagem socialmente criada a respeito dos jovens pobres, quase sempre associada à violência e à marginalidade, eles também se posicionam como produtores culturais.' Entre eles, a música é o produto cultural mais consumido e em torno dela criam seus grupos musicais de estilos diversos, dentre eles o rap e o funk Nesses grupos estabelecem trocas, experimentam, divertem-se, produzem, sonham, enfim, vivem determinado modo de ser jovem.
Autores como Mannheim (1982) ou Melucci (1994) recomendam que devemos estar atentos às expressões juvenis, pois estas podem ser a ponta de um iceberg, que torna visiveis as tensões e contradições da sociedade em que vivem. Se seguimos essa orientação, cabe-nos perguntar: 0 que pode estar significando esse fenômeno? Será que é apenas uma moda passageira, como tantas outras patrocinadas pela indústria cultural? Ou pode estar nos dizendo sobre novos modos de ser jovem neste inicio de século ou mesmo apontando para novas formas de socialização vivenciadas por eles?

A nossa hipótese é de que a centralidade do consumo e a da produção cultural para os jovens são sinais de novos espaços, de novos tempos e de novas formas de sua produção/formação como atores sociais. Ou seja, apontam para novas formas de socialização, nas quais os grupos culturais e a sociabilidade que produzem vêm ocupando um lugar central. É o que nos propomos discutir neste texto. Interessa-nos apreender os significados que os jovens atribuem à experiência de participação nos grupos musicais, buscando compreender os sentidos que adquirem no processo de construção social de cada um deles. Para tanto, tomaremos como objeto de análise jovens da periferia de Belo Horizonte que participam de grupos musicais ligados aos estilos rap e funk. Iniciaremos com uma discussão sobre a noção de socialização,

1.Nos limites deste texto não cabe desenvolver uma discussão sobre violência e juventude, que se torna cada vez mais séria, com índices alarmantes de homicídios envolvendo jovens. Como denunciou 0 juiz Geraldo Claret, do Juizado da Infância e da Juventude de Belo Horizonte, morrem assassinados na cidade, por ano, uma média de 400 jovens de 12 a 20 anos. (Estado de Minas 13/10/2001). Mas é importante ressaltar a necessidade de uma maior problematização deste tema, superando as análises reducionistas que fazem uma vinculação linear da violência à pobreza ou, pior, levam a generalizações preconceituosas que fazem de todo jovem pobre um marginal em potencial, aumentando o fosso social já existente na nossa "cidade partida".

20s dados empíricos utilizados são resultado da pesquisa que resultou na tese de doutorado intitulada:A música entra em cena: $\alpha$ ap e of unkna socialização da juventude em Belo Horizonte,apresentada na Faculdade de Educação da USP em julho de 2001. Nela, partimos de um universo de 146 grupos musicais juvenis, de onde foram escoIhidos seis grupos derape funk a partir dos quais discutimos os processos de socialização. 
seguida por uma contextualização social dos jovens pesquisados. Com esse pano de fundo, desenvolveremos uma análise dos estilos rap e funke os significados que adquirem para os jovens.

\section{Juventude e socialização}

Na sociologia clássica, desde Durkheim, desenvolveram-se reflexões sobre a socialização a partir de diversas perspectivas, de acordo com o próprio contexto histórico, com concepções distintas de sociedade, dos atores sociais e das interações, exprimindo modelos determinados de sociedade e de cultura. Vários autores questionam se tais paradigmas, produzidos no contexto de certa concepção clássica de sociedade, são capazes de explicar os processos sociais que ocorrem na sociedade contemporânea, no bojo das profundas transformações que vêm ocorrendo nas últimas décadas.

Van Haetcht (1992), por exemplo, evidencia que, nesses paradigmas anteriores, a teoria da socialização dicotomiza a lógica estrutural e a lógica da atuação, compreendendo a socialização reduzida a um treino, que gera a interiorização de um "programa" a ser executado no futuro. Propõe entendê-la como um processo adaptativo, articulando ator e estruturas, em que os efeitos da socialização seriam apenas os parâmetros da ação, não sendo, assim, irreversíveis. Nessa mesma direção, Dubet (1994) aponta uma série de limites na sociologia clássica para a compreensão dos processos socializadores contemporâneos. Para ele, tais teorias buscam entender e explicar a socialização na perspectiva da reprodução social, perguntando como as instituições garantem a continuidade social. Nelas o ator é o sistema, ou seja, a conduta, a subjetividade, os sentimentos são interiorizações de uma posição objetiva do sistema. Dessa forma, explicar os indivíduos é explicar a determinação de seu lugar social sobre sua personalidade, uma vez que haveria um processo de interiorização do social. 0 objeto de análise se constitui em torno da religião, da família e/ou da escola, instituições que permitem "fabricar" os atores pelo sistema.

0 autor propõe uma outra forma de conceber os processos de socialização no contexto de uma sociedade em mutação, numa superação dos limites das teorias clássicas. Para Dubet, os atores e as instituições não são mais redutíveis a uma lógica única, a um papel e a uma programação cultural de condutas, como era pensada a socialização na sociedade industrial. Passa a ocorrer uma heterogeneidade de princípios culturais e sociais que organizam as condutas, com os atores podendo adotar simultaneamente vários pontos de vista. Há mutações globais dos quadros de referência, e nenhuma delas assume uma centralidade. Não há mais uma unidade do sistema e do ator. 0 ator não é totalmente socializado a partir das orientações das instituições nem a sua identidade é construída apenas nos marcos das categorias do sistema.

Para o autor existem três sistemas que formam o conjunto social, cada qual regido por uma lógica diferente: uma comunidade estruturada por uma lógica de integração; um ou mais mercados competitivos, dependendo de uma lógica da estratégia e um sistema cultural correspondente a uma lógica da subjetivação. Os indivíduos constroem-se socialmente através das experiências sociais, entendidas como a capacidade de o indivíduo articular esses tipos de ação, numa dinâmica que leva à constituição da subjetividade do ator e sua reflexividade. É a experiência social que articula o trabalho do indivíduo, que constrói uma identidade, uma coerência e um sentido às suas ações sempre dialogando com as lógicas de ação que já se encontram determinadas. Nessa medida a socialização e a formação dos sujeitos são entendidas como o processo mediante o qual os atores constroem sua experiência, evidenciando uma equação na qual os indivíduos se constroem e ao mesmo tempo 
são construídos socialmente (Dubet, 1997).

Nessa mesma direção, Charlot (2000) avança ao enfatizar um lugar à questão da ação do indivíduo sobre o mundo e no mundo. É nesse autor que nos inspiramos para definir determinada compreensão dos processos de socialização. Acreditamos que a socialização dos jovens pode ser compreendida como os processos por meio dos quais os sujeitos se apropriam do social, de seus valores, de suas normas e de seus papéis, a partir de determinada posição e da representação das próprias necessidades e interesses, mediando continuamente entre as diversas fontes, agências e mensagens que lhes são disponibilizadas. Em outras palavras, cada um dos jovens rappers ou funkeiros encontra-se em determinado grupo social, mas não se reduz a esse vínculo e ao que pode ser pensado a partir da posição desse grupo em um espaço social. Encontra-se em uma sociedade cujas agências clássicas de socialização, como veremos no caso da escola e do trabalho, se mostram frágeis, não sendo uma referência de valores e normas. Destas, a única instituição que continua tendo forte referência formativa é a família. Mas nenhuma delas, no contexto de uma sociedade em mutação, oferece certezas e seguranças como no passado. Como lembra Melucci (1996), as seguranças de que necessitamos devem ser construídas por nós mesmos.

Por outro lado, esse jovem vai abrindo outros espaços, nos quais o grupo de pares, o estilo ao qual adere e o consumo dos meios de comunicação de massa vão cada vez mais se constituindo como parâmetros de avaliação e organização das relações interativas com a realidade externa. Esse jovem tem acesso a múltiplas referências culturais, constituindo um conjunto heterogêneo de redes de significado que são articuladas e adquirem sentido na sua ação coti-diana. Assim, ele interpreta a sua posição social, dá um sentido ao conjunto das experiências que vivencia, faz escolhas, age na sua realidade: a forma como ele se constrói e é construído socialmente, como se representa como sujeito, é fruto desses múltiplos processos.

\section{O contexto: jovens pobres ou excluídos?}

Para melhor compreensão dos significados que os jovens pesquisados atribuem à vivência dos estilos rap ou funk é necessário contextualizar a realidade deles, apreendendo a forma como elaboram o conjunto das experiências que vivenciam no cotidiano. Por mais óbvio que possa parecer, é importante ressaltar que nenhum deles é um rapper ou funkeiro vinte e quatro horas ao dia. No cotidiano, a maioria deles trabalha, alguns estudam, possuem família, vivenciam conflitos, divertem-se, amam, sofrem, possuem desejos e propostas de melhoria de vida. Privilegiaremos, assim, as instâncias do trabalho, da escola e da família para traçar o contexto em que se inserem.

Os jovens rappers e funkeiros pesquisados estão situados no limiar da precariedade. Praticamente, todos eles começaram a trabalhar muito cedo, em ocupações típicas de adolescentes pobres, tais como lavar carros e ser office-boy. Além de ser uma forma de contribuir em casa, o trabalho era a condição para a vivência da condição juvenil:

A época do lava-jato foi a época que eu mais tinha condição. Eu ganhava superpouco, eu fazia a feira de casa, eu comprava o frango, entendeu, eu tinha a minha roupa, eu bebia, eu namorava... lá a gente ralava sábado, entendeu, sábado tinha vez que eu saía oito horas de lá, meu. Chegava em casa, deitava no tapete do meu quarto, todo sujo de graxa. Dormia até umas nove horas, aí

3Reafirmo que estou me baseando na realidade dos dezoito integrantes dos três grupos derape três defunkpesquisados. Esses jovens se situam, na sua maioria, na faixa etária entre 17 e 24 anos, sendo que apenas quatro deles estão acima dessa idade. Catorze deles são solteiros, morando com os pais, e apenas quatro são casados. 
tomava um banho, jantava. Tinha uma garrafa de vinho na geladeira, eu abria, tomava o vinho, ia pra rua. Chegava e encontrava no Vilarinho com a turma, aí a gente dançava e zoava pra caralho... (Nilson, 26 anos, rappet

Como evidenciam inúmeras pesquisas, o trabalho juvenil não pode ser compreendido apenas pelo contexto de pobreza em que vivem os jovens. Aparece também como condição para maior autonomia e liberdade em relação à família, pela possibilidade do consumo de bens e pela garantia de um mínimo de lazer, enfim, é o trabalho que possibilita a vivência da própria condição juvenil. Mas o que podia ser visto como uma etapa inicial, tornou-se uma constante em suas trajetórias no mercado de trabalho. Nenhum deles conseguiu se qualificar em alguma profissão e todos sobrevivem ainda de bicos e empregos precários. Expressam o contexto de uma crise pela qual passa a sociedade brasileira, o que afeta as instituições clássicas responsáveis pela socialização. Essa crise se manifesta na desestruturação do mercado de trabalho e no aumento do desemprego juvenil, atingindo mais diretamente os jovens pobres (Pochmann,1998).

Dessa forma, o mundo do trabalho não Ihes aparece como um espaço de escolhas, ao contrário, nenhum deles gosta do que faz, não vendo nessas atividades nenhuma centralidade além da renda. Para muitos deles, o envolvimento com a música implicou uma tensão entre o tempo do trabalho e o tempo da música:

Chegava dentro de uma firma e minha cabeça num era pra aquilo lá, trabalhei em muitos lugares, cara, mas minha cabeça num aceitava... era aquele trauma, ficava nervoso porque eu pensava:"Pô, eu tenho de fazer é música, o meu negócio é aquilo lá, é só com isso que eu me entretenho, é nisso que eu tenho uma vontade, cara!" (Pedro, 24 anos, rappet
Eles fazem uma dissociação entre o emprego atual e a carreira musical: um é aquele ao qual se vêem coagidos a exercer, cuja valência é instrumental; a outra, a carreira musical, aponta para a possibilidade de um trabalho que é visto como fonte de satisfação pessoal e como atividade criativa. Como diz um deles, gostar de trabalhar eu até gosto; a questão não é de não gostar de trabalhar, é de fazer o que não gosto...

Podemos entender a postura desses jovens como uma recusa das condições que a sociedade lhes oferece para sua inserção social. Por intermédio da música, experimentam a possibilidade de uma atividade com sentido e não querem aceitar a sujeição às alternativas que lhes são postas. Dessa forma, o trabalho não constitui fonte de expressividade. Reduz-se a uma obrigação necessária para uma sobrevivência mínima, perdendo os elementos de uma formação humana que derivavam de uma cultura que se organizava em torno do trabalho.

Esses jovens são exatamente os menos contemplados pela escola. A maioria deles foi excluida da escola nos mais variados estágios e, grande parte, antes de completar o ensino fundamental, com uma trajetória marcada por repetências, evasões esporádicas e retornos, até a exclusão definitiva. Apenas quatro jovens continuam a estudar, alguns no ensino fundamental e outros no ensino médio, sendo possivel perceber que os significados que atribuem a essa experiência é bem diversa. Para aqueles que ainda estudam, a escola aparece como uma instituição distante e pouco significativa:

Antes eu não gostava de da escola de jeito nenhum... Agora, tipo assim, eu tive que gostar porque é uma coisa que eu dependo dela, tipo assim, eu aprendi a gostar porque eu sei que preciso... mas se desse pra viver sem escola eu preferia viver sem escola... (Flavinho, 17 anos, funkeiro) 
A escola se realiza como uma provação, uma "chatice necessária" para um credencia-mento que tem um peso relativo no mercado de trabalho. Já para outros, a experiência escolar carrega um sentido negativo, contribuindo para reproduzi-los na condição de subalternos:

Eu larguei a escola depois que tomei a segunda bomba na $5^{\text {a }}$ série, isso eu tava com 14 anos, já tinha tomado pau na $2^{\text {a }}$, e na $5^{\text {a }}$ série eu tomei dois. Minha lembrança da escola é péssima, eu nem gosto muito de tocar nesse assunto não. Por que assim, quando eu era novo eu era muito complicado, ocê entendeu? Eu contestava muito, eu tenho um senso crítico muito grande comigo mesmo. Então a escola nunca aguçou esse lado meu, entendeu? A professora falava lá, eu não gostava desses papos lá... eu sempre contestando o que ela falava. Sempre batendo de contra, pelo menos o que eu achava. Ignorando, também, o lado da ignorância minha. Eu queria mais era brincar, e sempre caía na turma dos mais bagunceiros. Ah, sei lá, escola pra mim era um saco. Resumindo, era um saco mesmo, era muita pouca coisa de escola que eu gostava mesmo... (João, 21 anos, rapper)

A construção de auto-imagens, como a de "mau aluno", ou as reprovações são alguns dos mecanismos internos à organização escolar que terminam por levá-los à exclusão. A forma como muitos deles elaboram a saída da escola é marcada pela culpa e pelo arrependimento: consideram-se os únicos responsáveis pela falta de qualificação na qual se encontram atualmente. Não levam em conta os mecanismos sociais perversos que interferiram nas suas escolhas, com um sentimento de culpa que tende a minar a auto-estima.

Dessa forma, as experiências escolares desses jovens, mesmo apresentando situ- ações específicas, deixam claro que a instituição escolar é pouco eficaz no seu aparelhamento para enfrentar as condições adversas de vida com as quais vieram se defrontando, não constituindo referência de valores no seu processo de construção como sujeitos.

A situação desses jovens se vê agravada pelo encolhimento do Estado na esfera pública, que não oferece soluções por meios de políticas que contemplem a juventude, gerando privatização e despolitização das condições de vida. Além da falta de políticas nas áreas básicas de emprego ou saúde, se defrontam com a falta de acesso aos bens culturais. Todos afirmam não freqüentar cinema com a regularidade com que gostariam de fazê-lo; grande parte nunca freqüentou um teatro; todos gostariam de fazer algum curso ligado à música, entre outros exemplos, e não o fazem por falta de recursos financeiros.

Para aqueles que se encontram desempregados, o cotidiano se mostra vazio. Andando pelos bairros de periferia nos dias de semana, é possível ver dezenas de jovens pelas ruas e calçadas, conversando em grupos ou simplesmente sentados, passando o dia sem ter o que fazer, sem acesso a equipamentos sociais, como centros culturais ou mesmo praças públicas, sem espaços e tempo que os estimulem, que ampliem as suas potencialidades. Não têm outra alternativa a não ser levar uma vida empobrecida não só de recursos materiais, mas, principalmente, de recursos simbólicos que os capacitem a enfrentar as transformações pelas quais a sociedade vem passando. Talvez esteja aí uma das principais razões que levam os jovens pobres a se envolverem com as drogas e a marginalidade. Para os jovens ligados aos grupos musicais, existe pelo menos o sonho de se tornarem cantores, gravar, fazer sucesso. Um sonho que, independentemente das possibilidades da sua realização, dá um sentido ao cotidiano deles. 
Nesse contexto, as famílias se vêem cada vez mais responsabilizadas por garantir a reprodução dos seus membros, não contando com quem possa "ajudá-las a se ajudar". Como lembra Telles (1992, p. 89),

a centralidade da família pode ser vista como registro de uma sociedade na qual a chamada questão social foi equacionada nas formas de uma pobreza colonizada, despolitizada e privatizada nas suas formas de manifestação.

Não é sem razão que para a grande maioria desses jovens a família ocupa um lugar central: as relações que estabelecem, a qualidade das trocas, os conflitos e os arranjos existentes para garantir a sobrevivência são dimensões que marcam a vida de cada um, constituindo-se um filtro por meio do qual traduzem o mundo social, significando um espaço de experiências estruturantes. Nesse sentido, a familia ainda é uma das poucas instituições do mundo adulto com a qual esses jovens podem contar.

Uma primeira tendência seria caracterizar esses jovens como excluídos. Mas tanto Castel (1995) quanto Martins (1997) nos advertem sobre a imprecisão desse conceito, criticando certo fetichismo da idéia da exclusão que tende a suprimir as mediações existentes entre a economia e outros níveis e dimensões da realidade social. Para Martins (1997, p. 20), o modelo socioeconômico brasileiro implementa

uma proposital inclusão precária e instável, marginal. São políticas de inclusão de pessoas nos processos econômicos, na produção e circulação de bens e serviços, estritamente em termos daquilo que é racionalmente conveniente e necessário à mais eficiente reprodução do capital.

Assim, é mais esclarecedor caracterizálos como jovens pobres, vivenciando formas frágeis e insuficientes de inclusão num contex- to de uma nova desigualdade social: aquela que implica o esgotamento das possibilidades de mobilidade social para a maioria da população. Nela, a pobreza mudou de forma, de âmbito e de conseqüências. Se para as gerações anteriores estava posta, mesmo que remotamente, a perspectiva de mobilidade por meio da escola e/ou do trabalho, para os jovens de hoje essa alternativa não mais se apresenta. Nesse sentido se instaura o quadro da criset: os velhos modelos nos quais as instituições tinham um lugar socialmente definido já não correspondem à realidade. 0 trabalho não oferece mais um tipo de regulação da sociedade, a escola não cumpre a função de moralização e mobilidade social, e novos modelos ainda não estão delineados. 0 que antes se caracterizava como possibilidade de passagem do momento da exclusão para o momento da inclusão, hoje, para parcelas de jovens pobres, está se transformando em meio de vida.

Vivemos no Brasil uma situação paradoxal. Nas últimas décadas vem ocorrendo uma modernização cultural, consolidando uma sociedade de consumo, ampliando o mercado de bens materiais e simbólicos, mas que não é acompanhada de uma modernização social. Assim, os jovens pobres inserem-se, mesmo que de forma restrita e desigual, em circuitos de informações, por meio dos diferentes veículos da mídia, e sofrem o apelo da cultura de consumo, estimulando sonhos e fantasias, além dos mais variados modelos e valores de humanidade. A esfera do consumo cultural torna-se um momento importante para as trocas sociais, propiciando o acesso aos estilos, por exemplo. No caso dos jovens pesquisados, foi como consumidores culturais de músicas, CDs, shows de rap e funkque eles puderam se transformar em produtores e, nessa experiência, ressignificar a sua trajetória, criando formas próprias de ser jovem.

4 A noção de crise é utilizada não no sentido de ruptura, de caos, mas de mutações e recomposições profundas nas relações sociais, nas quais se esgotam modelos anteriores e ainda não estão delineadas as novas relações, como sugere Melucci (1994). 
Mas se há uma ampliação de possibilidades, há uma restrição ao seu acesso, sendo uma das faces perversas da nova desigualdade. Os jovens pobres se vêem, assim, privados da escola, do emprego, acompanhados da limitação de meios para a participação efetiva no mercado de consumo, da limitação das formas de lazer, da limitação dos direitos de vivenciar a própria juventude e, o que é mais sério, vêem-se privados da esperança.

É nesse contexto que temos de entender os significados que adquirem para esses jovens a experiência nos grupos musicais, sejam de rapou funk

\section{Juventude e música: o rap e o funk}

Em outro artigo, ${ }^{5}$ procurei discutir a importância da música para os jovens, ressaltando que a relação entre a música e a juventude é uma construção histórica, iniciada principalmente a partir dos anos 1950 com ojazz Mas foi a partir da década de 1970 que essa relação adquiriu maior visibilidade, tanto pela expansão quanto pela diversificação de estilos, além de os jovens se posicionarem mais diretamente como produtores musicais, e não apenas como fruidores. Essa mudança foi resultado de uma série de fatores, dentre eles da popularização da aparelhagem eletrônica e mesmo do estímulo do movimento punk, com o seu lema do it yourself- "faça sua música, o seu estilo, não se acomode na postura do espectador vazio"- apontando uma forma possível de produzir arte no contexto da cultura de massas.

É também dessa mesma época uma grande diversificação social da juventude urbana, com a crescente inserção dos jovens pobres no mercado de trabalho, gerando a ampliação do consumo juvenil, principalmente na moda e no lazer, e criando espaços próprios de diversão nas periferias dos grandes centros, como os bailes e sons Desde então, a visibilidade social dos jovens vem se dando principalmente por intermédio dos grupos culturais existentes, sucedendo-se uma lista considerável de movimentos e tendências, umas mais passageiras, outras ainda persistentes, envolvendo jovens de diferentes camadas sociais, com diferentes projetos, níveis diferenciados de envolvimento, mas tendo em comum uma proposta de estilização e a eleição de determinado ritmo musical. São os punks nas suas diversas variações, como o trash, o hardcore, o anarco-punk São os darkş o heavy metal o reggae É nessa esteira que podemos situar o hip hop e o funk

Esses dois estilos possuem uma mesma origem - a música negra americana -, que incorporou a sonoridade africana, baseada no ritmo e na tradição orais. Eles são herdeiros diretos do soulque, depois de ser a trilha sonora dos movimentos civis americanos da década de 1960 e um símbolo da consciência negra, perdeu essas características revolucionárias com a sua massificação. 0 funk radicalizou o soul empregando ritmos mais marcados e arranjos mais agressivos, mas o funktambém sofreu um processo de comercialização, com a remoção de sua base cultural, tornando-se uma música mais digerível do grande público.

0 rapsurgiu, nesse período, como mais uma reação da tradição black Ele surge junto a outras linguagens artísticas, como a das artes plásticas, a do grafite, da dança - o break - e da discotecagem - o DJ. Juntas tornaramse os pilares da cultura hip hop fazendo da rua o espaço privilegiado da expressão cultural dos jovens pobres. 0 rap, palavra formada pelas iniciais da expressão rhythm and poetry (ritmo e poesia), tem como fonte de produção a apropriação musical, sendo a música com-

$\mathbf{5}$ Ver Dayrell (1999).

GEstou entendendo "estilo" como uma manifestação simbólica das culturas juvenis, expressa em um conjunto mais ou menos coerente de elementos materiais e imateriais, que os jovens consideram representativos da sua identidade individual e coletiva. Na construção de um estilo, os jovens escolhem determinado gênero musical que consomem, criam um tipo de visual e espaços próprios de diversão e atuação. Assim o estilo pressupõe o cruzamento dos campos do lazer, do consumo, da mídia e da criação cultural (Dayrell,1999; 2001). 
posta pela seleção e combinação de partes de faixas já gravadas, a fim de produzir uma nova música. "Mixando" os mais variados estilos da black music o rapcria um som próprio, pesado e arrastado, reduzido ao mínimo, no qual são utilizados apenas bateria, scratch e voz. Mais tarde, essa técnica seria enriquecida com o surgimento do sampler. Desde então, o rap aparece como um gênero musical que articula a tradição ancestral africana com a moderna tecnologia, produzindo um discurso de denúncia da injustiça e da opressão a partir do seu enraizamento nos guetos negros urbanos.?

No Brasil, a difusão do funke do hip hop remonta aos anos 1970, quando da proliferação dos chamados "bailes black" nas periferias dos grandes centros urbanos. Embalados pela black musicamericana, principalmente o soule o funk milhares de jovens encontraram nos bailes de finais de semana uma alternativa de lazer até então inexistente. Desenvolveram-se nos mesmos espaços, por jovens de uma mesma origem social: pobres e negros, na sua maioria. Tanto a música rap e funk quanto o seu processo de produção continuam apresentando algumas semelhanças, fiéis à sua origem, tendo como base as batidas, a utilização de aparelhagem eletrônica e a prática da apropriação musical. Os dois estilos são mais democráticos, não tendo como pré-requisito a utilização de instrumentos musicais, o domínio de habilidades técnicas musicais nem mesmo maiores custos com a montagem e a organização dos locais para exibição pública. Para os jovens da periferia que, geralmente, não têm acesso a uma formação musical, o rap e o funksão dos poucos estilos que lhes permitem realizar-se como produtores musicais e artistas. Não é sem razão que grupos de rap e duplas de $\mathrm{MCs}^{10}$ tendem a cantar apenas suas próprias músicas, sendo raro que cantem músicas de outros grupos.

Mas, no processo da sua elaboração e reelaboração nos grandes centros urbanos brasileiros, o rape o funkforam assumindo características próprias. As letras expressam outros sentidos, as formas de sociabilidade possuem especificidades, assim como os rituais que constituem cada um desses estilos, ganhando significados próprios para os jovens que deles participam. É o que veremos a seguir na descrição dos grupos de rape duplas de funkem Belo Horizonte. O scratch consiste na obtenção de sons, girando manualmente o disco sob a agulha em sentido contrário, produzindo efeitos sonoros próprios.

\section{Os jovens e o rap}

0 rapcomeçou a difundir-se em Belo Horizonte a partir do final dos anos 1980 . Desde então, veio se construindo uma cena rap que, mesmo ocupando um espaço marginal no circuito cultural, se mantém viva e atuante, apesar das oscilações entre momentos de latência e de maior visibilidade. Ao mesmo tempo, existe uma parte ainda mais submersa, formada por um sem-número de jovens que se reúnem e formam seus grupos nos bairros por simples diversão, na maioria das vezes com uma curta trajetória, sem se tornarem conhecidos no próprio meio hip hop. Durante todo esse tempo existiu e existe ainda uma rotatividade de grupos muito grande, vários se desfazendo ou mesmo trocando de integrantes, e muito poucos permanecendo do início do movimento na cidade.

Os três grupos pesquisados expressam essa realidade:

- 0 grupo Processo Hip Hop - Formou-se no início de 1998 e teve uma vida relativamente curta, extinguindo-se no final de 1999. Era formado por três jovens, com idade variando de 17 a 22 anos, sendo dois negros

7.A mixagem é a mistura de músicas feita pelo DJ, que utiliza 0 aparelhomixer.

a 0 scratchconsiste na obtenção de sons girando manualmente 0 disco sob a agulha em sentido contrário, produzindo efeitos sonoros próprios.

aPara maiores detalhes da história dohip hop,ver, dentre outros, Dayrell (2001), Sposito (1993), Silva (1998) e Tella (2000). Para uma história dofunkver Vianna (1987) e Herschmann $(1997,2000)$.

10. $0 \mathrm{MC}$ é o mestre de cerimônia, como se autodenominam os cantores defunk quase sempre formados por duplas. 
e um branco, todos moradores do Aglomerado da Serra, região centro-sul da cidade. É um exemplo de grupos que se formam e se desfazem sem ganhar maior projeção na cena $r a p$, não tendo CD nem fita demo gravados.

- 0 grupo Máscara Negra -É um grupo formado, desde 1996, por três integrantes, todos negros, sendo dois com 20 anos e um com 27 anos. Tem projeção na cena rap tendo sido escolhido o melhor grupo de rapem 1997. 0 grupo não tem nenhum CD gravado, apenas fita dema

- 0 grupo Raiz Negra - Formou-se no início dos anos 1990, sendo o mais antigo dos grupos pesquisados e um dos poucos desse período que ainda permanecem ativos. É formado por quatro integrantes, três deles negros, com idade variando de 24 a 28 anos. Dentre os grupos pesquisados, é o que apresenta o perfil mais profissional, possuindo um CD gravado.

A experiência desses jovens nos grupos musicais revela múltiplos significados, interferindo diretamente na forma como se constroem e são construídos como sujeitos sociais e como elaboram determinada identidade individual e coletiva.

Um primeiro aspecto a ser salientado é a dimensão da escolha. Recuperando a trajetória dos grupos, constatamos inicialmente que todos os jovens aderem ao estilo como consumidores do gênero musical. A passagem para a condição de produtores significou para todos um processo de envolvimento gradativo. É possivel perceber alguns fatores comuns que explicam a escolha que realizam: o lugar social que ocupam e o capital cultural a que têm acesso, os poucos pré-requisitos do rap para a produção cultural, a identidade com o ritmo e a temática abordada pelo estilo, dentre outros. Significa dizer que a escolha e a adesão ao estilo são frutos de uma complexa trama na qual estão presentes os determinantes sociais, mas também a expressão da subjetividade.

Mas o exercício da escolha não se dá apenas no momento da adesão ao estilo. Os jovens revelam que em vários momentos ocorreram dúvidas e crises, quando se perguntavam a si mesmos se o caminho era realmente o da música. Alguns se afastaram para depois retornar; outros, como o Processo Hip Hop se dissolveram. Mostram, assim, que a trajetória no estilo não está separada da vida, com as suas dúvidas e perplexidades, quando deparamos sempre com a necessidade de escolher.

Outro aspecto que ganha importância na vida de cada um é a experiência, comum a todos, como produtores culturais. Como já observamos, todos só cantam suas próprias músicas, sendo muito raro cantarem músicas de outros grupos, o que envolve um exercício da criatividade. Geralmente o processo de produção das músicas é individual e coletivo, sendo um momento rico de trocas entre os integrantes do grupo quando todos discutem, opinam e interferem na criação. Todos são autodidatas, mas expressam o desejo de estudar música e algum instrumento, condição essencial para a profissionalização.

Em cada grupo sempre existe um que tende a compor as "rimas", através das quais desenvolvem uma interpretação poética de si mesmos e da condição social em que vivem. Para muitos deles, compor a letra é um momento de extravasar, de traduzir em forma de poesia os sentimentos que vivenciam:

Escrever as letras é tipo assim, uma muleta, quando eu tô sentindo muita melancolia, quando eu tô sentindo muitas vezes só, eu sento e escrevo... Eu sempre escrevo quando eu tô muito melancólico... (Nilson, 25 anos)

Nessa produção poética, a estrutura das letras, a fidelidade ao território e a explicitação de uma temática social são elementos identificadores do rap em qualquer lugar, seja no Brasil ou nos Estados Unidos. Ao mesmo tempo, o conteúdo poético tende a refletir o lugar social concreto onde cada jovem se situa e a forma como elabora suas vivências, numa postura de denúncia das 
condições em que vive: a violência, as drogas, o crime, a falta de perspectivas, quando sobreviver é o fio da navalha Mas também cantam a amizade, o espaço onde moram, o desejo de um "mundo perfeito", a paz. Como diz um deles, eu sou um mero observador do comportamento do ser humano... num tenho estudo, num sou nada, mas eu fico observando o comportamento das pessoas Nesse sentido, o rap pode ser visto como uma crônica da realidade da periferia.

Eles atribuem a si mesmos o papel de "porta-vozes" da periferia, um dos elementos da identidade do estilo. Alguns deles se atribuem a "missão" de problematizar a realidade em que vivem através das músicas que cantam, com a pretensão de "conscientizar os caras" dos problemas e riscos que o meio social thes impõe:

0 que a gente passa com a música é um pouquinho de consciência, de amor próprio, de auto-estima... a gente quer levar o nosso povo pra frente, a minha vontade é essa, de revolucionar, abrir a cabeça de um e de outro para eles terem consciência e saber o que está fazendo, aprender o direito deles, nem que for um pouquinho, entendeu? (Pedro, 26 anos, rappey)

Para muitos desses jovens, o rap torna-se uma forma de intervenção social, mas em outros moldes. Por meio da linguagem poética, do corpo, do lazer propõem uma pedagogia própria, que tem como um dos instrumentos a polêmica. Talvez esteja aí uma das dificuldades de estabelecerem um diálogo com as organizações políticas do mundo adulto, como sindicatos, partidos e até mesmo o movimento negro, diante dos quais se mostram desconfiados, mantendo distanciamento. Ao mesmo tempo, os grupos Máscara Negra e Raiz Negra desenvolvem esporadicamente algumas atividades sociais, como oficinas de hip hopem escolas públicas e festas beneficentes.
Um momento muito significativo para todos os grupos são as apresentações que realizam. Para muitos, é no palco que se sentem verdadeiramente rappers $A$ freqüência e o caráter dos shows são diferentes entre os grupos: enquanto o Processo Hip Hop tem um número limitado de apresentações e sempre em eventos no próprio bairro, o Raiz Negra e o Máscara Negra se apresentam com mais regularidade tanto em eventos quanto em festas promovidas em danceterias no centro da cidade. Todos os jovens reforçam a importância dos shows na vida de cada um. Alguns ressaltam a emoção e o prazer - a maior adrenalina - de estarem no palco mostrando o resultado da sua produção. Outros ressaltam a auto-afirmação do que os shows representam, sendo uma forma de resgatar a própria dignidade:

Trabalhava de faxina e o maior orgulho meu era estar lá fazendo faxina e quando eu chegava no palco eu era um rapper, entendeu? Eu tenho pouco estudo, nunca tive um emprego bom, mas eu tenho uma cabeça pra revolucionar, eu tenho dignidade porque eu chego em casa e sou um rapper, tenho uma missão... (Pedro, Máscara Negra)

Outros ainda enfatizam a importância de serem reconhecidos no próprio meio em que vivem. Podemos dizer que, para esses jovens, aderir ao estilo possibilitou-lhes a abertura de novos espaços, onde eles passaram a se colocar na cena pública em outros termos, como artistas, como criadores, como sujeitos de um projeto. Nesse sentido, o rapé um meio de que se servem para articular uma auto-imagem positiva, uma forma de se afirmarem como "alguém" numa sociedade que massifica e os transforma em anônimos. Ao mesmo tempo, através das letras das músicas, do corpo e do visual que valorizam a estética negra, na afirmação positiva do espaço da periferia, o rap possibilita a muitos desses jovens reelaborar a experiência social imediata em termos culturais, traduzida em forma de autoconsciência 
diante do processo de segregação espacial e dos preconceitos sociais e raciais que se acirram em Belo Horizonte, possibilitando a construção de uma identidade positiva como pobres e negros.

Por outro lado, podemos constatar que o estilo proporciona algumas circunstâncias centrais na construção de uma identidade juvenil: a música e um quadro de referências comuns por meios dos quais fazem uma leitura da realidade; as práticas coletivas, tanto na produção musical quanto na fruição do lazer; além de um conjunto de ícones que os distinguem do mundo adulto.

Para grande parte deles, a adesão ao estilo se deu na adolescência, coincidindo com um momento no qual procuravam romper com tudo aquilo que os prendia ao mundo infantil, buscando outros referenciais para a construção da identidade fora da família, onde o grupo de amigos passa a cumprir um papel fundamental. Desde então, o rap funcionou como uma referência para a escolha dos amigos, bem como das formas de ocupação do tempo livre. Inicialmente centrada no bairro, o envolvimento com o estilo e a participação nos eventos proporcionaram a quase todos uma ampliação da rede de relações, estimulando-os a se apropriarem da cidade.

As redes de relações construídas em torno do rapapresentam densidades distintas, o que leva os jovens a distinguir entre "colegagem" e amizade. Aquela é mais fluida, e esta é uma relação que traz uma conotação familiar, de "irmão", quase sempre presente nas relações que se constroem no grupo musical. Em cada um deles a rotina de encontros entre os seus integrantes é variável, dependendo do ritmo dos ensaios e da disponibilidade para o lazer de cada um.

Uma característica desses grupos é a sua rotatividade. Todos narram uma trajetória na qual há um contínuo nascer e renascer de grupos, fazendo com que o percurso de crescimento e as experiências de agregação sejam muito dinâmicos e singulares. Essa descon- tinuidade dos grupos e das relações pode ser vista como uma característica da própria da condição juvenil, e não tanto do estilo em si.

Mas o grupo é sempre uma referência muito forte, aparecendo como um espaço privilegiado de investimento emocional e de construção de relações de confiança, numa complexa trama de conflitos e acordos, em um equilíbrio instável. Mas em todos eles parece que a individualidade dos seus membros é assegurada, fazendo com que as relações sejam uma contínua negociação com as diferenças e os desejos individuais. Essa característica, perceptível em todos os grupos, parece mostrar a necessidade que os jovens têm de garantir espaços, tempos e projetos individuais no coletivo. Podemos dizer, com Torti (1994, p. 62), que sinalizam para novas formas da sociabilidade na sociedade contemporânea, que "induzem dinâmicas recíprocas de distanciamento e aproximação. Nós nos aproximamos para depois nos distanciarmos num jogo entre necessidades de agregação e exigências de espaços de individuação...”.

Mas as relações não se reduzem ao grupo, estendendo-se a uma rede de "colegagem". Encontram-se nos momentos de lazer, nas festas e nos eventos. Mesmo não estabelecendo relações mais próximas, existe uma solidariedade própria para com quem se sente parte de um mesmo movimento. Os programas de lazer são um pouco desiguais no ritmo e na qualidade, dependendo do momento de vida de cada um. Para aqueles mais novos, existe uma procura constante de programas, mobilizados pela diversão e pdo desejo de estarem juntos com a turma de amigos. A centralidade do lazer e dos amigos tende a se transformar com o avanço da idade, dos compromissos afetivos com as esposas ou namoradas e das responsabilidades que cada um vai assumindo, diminuindo a sua intensidade. No geral, os programas mais comuns são a freqüência à casa de amigos, os bares e as festas de rap que lhes abrem as possibilidades de um lazer além da sua região, gerando um desloca- 
mento que desafia a lógica perversa da metrópole, que tende a segregá-los nos bairros distantes da periferia, tornando-se uma forma possível de ocupação da cidade.

\section{Os jovens e o funk}

0 funk em Belo Horizonte é herdeiro direto dos bailes blackque se difundiram na periferia da cidade desde os anos 1970. Até o início da década de 1990, os jovens freqüentadores dos bailes não se identificavam ainda como funkeiros, agregando-se em torno da música e no prazer da dança. Nos bailes não havia, como não há, uma fidelidade a um estilo musical, convivendo os mais diferentes sons eletrônicos, além do rock e até do pagode. Foi nos meados dessa década que começam a aparecer os "mestres de cerimônias" (MCs) locais, duplas ou grupos que cantavam suas músicas, influenciados pelo processo de nacionalização do funkiniciado no Rio de Janeiro. Foi quando começou a se delinear, de fato, o funk como estilo, com os jovens se identificando como funkeiros A cena funk $\mathrm{na}$ cidade está presente no circuito cultural formal, em grandes danceterias e programas em rádios comerciais, mas também no circuito alternativo, nos bailes promovidos nos bairros, em quadras cobertas ou em escolas. Isso se deve à característica do estilo ser baseada nos bailes, um tipo de lazer que tradicionalmente atrai uma massa de jovens, quer se identifiquem como funkeiros, quer não.

0 funk, na forma como veio sendo construído em Belo Horizonte, é uma reelaboração do estilo difundido no Rio de Janeiro. Não significa, porém, que haja uma imposição linear da mídia na produção do estilo local. 0 que podemos constatar é um processo por meio do qual os jovens se apropriam do estilo difundido pelos meios de comunicação e o reelaboram a partir das condições concretas em que vivem, dos recursos de que dispõem, excluindo elementos ou ressignificando práticas.

Essa constatação põe em discussão os processos de difusão cultural no contexto de uma sociedade cada vez mais globalizada. 0 estilo funk mas também o estilo rap como expressões de uma cultura juvenil, não podem ser vistos como resultado de uma progressiva homoge-neização e massificação cultural, que homologaria a um único registro uma produção cultural juvenil, independentemente das condições estruturais concretas nas quais esses jovens estariam inseridos.

Ao contrário, a realidade dos grupos de rap e funke a história de cada um deles na cidade apontam para a existência de uma identidade própria a esses rapperse funkeiros Uma identidade que é fruto de uma reinterpretação dos sons e ícones associados a esses estilos, numa construção em que os sentidos que the são atribuídos expressam não só as condições estruturais nas quais se situam, mas também o próprio contexto cultural do meio social no qual vieram se construindo como sujeitos. Nesse sentido, concordamos com Sansone (1997, p. 171), quando questiona as teses de homogeneização de uma cultura juvenil, mostrando que, "ao lado de uma inquestionável globalização do universo da cultura juvenil, mantém-se uma série de aspectos locais, determinados por uma história local e contextos específicos", fazendo com que o "local" reinterprete o "global" de formas diferenciadas.

0 funkserá refletido a partir da realidade de três grupos pesquisados:

- A dupla Flavinho e Maninho - Ambos têm 17 anos, são brancos e moram com os pais. Começaram a cantar juntos no início de 1998 e atualmente fazem parte da equipe de DJ Vitor, a qual acompanham nas festas promovidas quase sempre na região norte da cidade. Já participaram de uma coletânea, com uma música gravada, além de vários CDs dema.

- A dupla Marcos e Fred - Cantavam juntos desde 1995, separando-se no final de 1998. Marcos é branco e tem 18 anos; Fred é negro e tem 19 anos. Eles são um bom exemplo de centenas de duplas que se formam, 
ganham alguma projeção, mas depois se desfazem, desiludidas com as perspectivas profissionais abertas pelo mercado musical. Por dois anos fizeram parte da equipe Funk Music do DJ Vitor, fazendo shows em Belo Horizonte, no interior de Minas Gerais e no Espírito Santo. Chegaram a ter suas músicas gravadas em dois CDs coletânea, que tiveram certa repercussão no meio funk em BH.

- Os Cazuza - 0 grupo formou-se em 1996, contando com quatro integrantes, todos negros, com idade variando entre 19 e 21 anos, sendo dois deles casados. Gravaram uma música em um CD coletânea, e na época se dividiam entre Belo Horizonte e Rio de Janeiro, tentando a gravação de um CD e a contratação por alguma equipe carioca.

Para esses jovens, aderir ao funk significa uma escolha, condicionada pela própria condição juvenil e o campo de possibilidades com o quais se deparam. Os fatores são semelhantes aos do rap a atração pelo ritmo e pela dança, a inexistência de maiores pré-requisitos para a produção musical e a influência da mídia. Mas o que parece ter influenciado de fato na decisão dos jovens em se tornarem MCs foi a identificação com o clima de alegria característico dos bailes, além de se destacarem diante dos seus pares e, principalmente, das meninas. Assim, a escolha pelo funkexpressa determinada forma de vivenciar a condição juvenil, com ênfase na diversão e na alegria que os bailes representam.

Da mesma forma como no rap os MCs se colocam como produtores culturais, mas pouco interferem na produção das bases musicais, uma tarefa dos DJs e de seus pequenos estúdios espalhados pela periferia. A música funk diferentemente da música $r a p$, não tem muito sentido em si mesma, cumprindo o seu papel efetivo como meio de animação dos bailes. Assim, a produção musical é caracterizada pela transitoriedade, por ser descartável, executada por um período relativamente curto, sendo logo substituída por outra. Os temas abordados são diretamente ligados ao universo das vivências juvenis, sendo comum abordarem as relações afetivas, a descrição de bailes e sua animação ou temas jocosos de situações ocorridas na cidade, além da exaltação das diferentes galeras. Outras características presentes em várias letras são a exaltação da paz e a crítica às brigas, numa resposta possível às situações de violência que ocorriam em alguns bailes."

Os temas expressam aspectos da vivência juvenil, não deixando de ser uma forma de refletirem sobre si mesmos e resgatarem o prazer e o humor que são tão negados em um cotidiano permeado pela lógica instrumental dominante, o que é coerente com o sentido que atribuem a si mesmos como MCs - serem os mensageiros da alegria, promovendo a agitação da galera.

O MC tem a obrigação de levantar a galera, incentivar mesmo, procurar passar uma paz, um agito, um ânimo pro pessoal pular mesmo, balançar, soltar os cachorros. Eu acho que o MC se expressa num modo de progredir a festa, fazer a festa encaminhar... (Flavinho,17 anos)

Se o rappers se vêem como porta-vozes da periferia, assumindo a dimensão da denúncia, os MCs se percebem como aqueles que contri-buem para criar a alegria da festa. Assumem, assim, dimensões particulares de uma mesma realidade, pontuando questões cruciais vividas pelos jovens.

Para esses jovens, ser um MC é uma experiência muito marcante. Assim como os rappers para os jovens funkeiroso estar no palco é fonte de emoção e prazer:

11. A pesquisa foi concluída antes da meteórica ascensão dofunk em 2000, não sendo pois objeto de análise desse trabalho. Mas é necessário pontuar a estigmatização promovida pela mídia, numa negação do estilo. As criticas sobre a qualidade das letras, o machismo, a erotização pública exagerada, etc., se são até certo ponto pertinentes, não levam em conta que os jovens expõem na cena pública as contradições do tecido social. Eles expressam, nas músicas e na dança, o caldo de cultura em que estão inseridos, fruto das condições em que vivem e do acesso que possuem aos bens simbólicos. Mais do que negar, é preciso aprofundar-se nos seus múltiplos significados. 
Nó, cara, é bom demais, né, ver aquele povo lá, a gente entrar e a massa ir ao delírio! Depois gritando: "Marcos e Fred! Marcos e Fred!" isso e aquilo, é gostoso demais... quando a gente sobe a gente treme, vem uma adrenalina! Dá uma vontade de esguelar, sair gritando, pular lá em baixo, curtir com o pessoal mesmo... (Fred, 18 anos)

Participar de shows e ter suas músicas difundidas nas rádios é o desejo mais imediato desses jovens. Essas são formas de participação que os destacam da multidão anônima, permitindo-lhes que se sintam alguém, com reflexos na auto-imagem. Ao mesmo tempo, proporciona-lhes descobrir e desenvolver as próprias potencialidades, como compor e cantar, tornando-os sujeitos criativos.

Como jovens, o grupo de amigos, ou a galera, constitui uma referência importante. E para esses MCs o grupo de amigos mais próximo se articula em torno do funk 0s companheiros de dupla tendem a se tornar os amigos mais próximos, sendo com eles que se encontram com mais freqüência, conversam sobre os problemas ou casos afetivos, numa relação mais íntima. Mas, assim como no rap, existe uma mobilidade muito grande de grupos e duplas, expressão de um momento de experimentações, típico da condição juvenil. Também o funk possibilitou a esses jovens a ampliação da rede de relações. Por meio dos bailes e shows, estabeleceram uma rede de relações amplas - os conhecidos - que não possui uma estrutura de coesão tão forte entre aqueles que dela participam: reconhecem-se no funk compartilham situações lúdicas, encontram-se nos bailes, sentindo-se parte de uma rede simbólica (Arce, 1999).

Para esses jovens, o estilo se constrói em torno dos bailes. Este é o elemento central a partir do qual se articula a identidade do funk É neles que podem expressar os outros elementos: o encontro com os amigos, o gosto pela música funk um determinado jeito de dançar e, principalmente, a oportunidade de se mostrarem como MCs. Podemos dizer que o baile funkrepresenta, antes de tudo, a celebração da amizade, o espaço por excelência para viverem dimensões constitutivas da condição juvenil: a explosão emocional da alegria, a identificação coletiva, o sentir-se em grupo. Vianna (1987, p. 58) reforça essa dimensão ao afirmar que "as pessoas freqüentam o baile não por um tipo de música, mas principalmente pelo ambiente, isto é, as outras pessoas, os amigos que se encontram e se divertem juntos, a alegria de viver em bando". Dessa forma, o baile funk constitui um espaço de sociabilidade, uma massa composta por grupos de amigos e galeras. Pode ser visto como uma opção de agrupamento metropolitano, numa reação possível à massificação da sociedade contemporânea.

Mas, afinal de contas, o que é ser funkeiro? A própria definição é fluida, como diz o Marcos:

0 funk é um modo de pensar, d'ocê estar de bem com a vida... mas não é uma idolatria, um tipo de religião como o rap, é mais um modo d'ocê estar solto com a vida, não num modo de não ter responsabilidade, mas d'ocê ser alegre...

Esse depoimento parece esclarecer os contornos da identidade desses jovens com o funk Ser funkeironão implica um conjunto de valores e comportamentos comuns, como uma "religião", mas constitui uma forma determinada de vivenciar as demandas dessa fase da vida. A identidade do funké a oferecida pelo estilo de possibilidades de viver e expressar as pulsões, os desejos e as necessidades que caracterizam a condição juvenil. Tanto é que não existe nenhuma exigência de coerência entre o comportamento pessoal e o comportamento como um MC, o que vimos existir entre os jovens que aderem ao rap. Outro elemento é a questão da cor e da origem social, quando parecem não estabelecer relações entre o funk 
e a identidade étnica ou como pobres. Enfim, podemos dizer que, diferentemente do rap, o funk não se coloca como espaço de construção de uma identidade como negros e pobres.

Essas considerações indicam que a identidade que esses jovens constroem como funkeirosé fluida e efêmera, uma imbricação com elementos simbólicos apropriados da cultura popular, da indústria cultural em geral, como manifestação cultural híbrida. Essa identidade apresenta-se como uma fronteira provisória e móvel, operando a partir de múltiplos registros na construção mais ampla de uma identidade desses sujeitos como jovens. Podemos dizer que o funké parte de determinado estilo de vida juvenil, um marco identitário que contribui para que esses jovens possam vivenciar e se afirmar como sujeitos numa determinada fase da vida.

\section{Os significados dos grupos musicais na socialização dos jovens}

As experiências desses jovens rappers e funkeirosnos levam a constatar que eles vieram se construindo e sendo construídos como sujeitos sociais numa complexidade de espaços e tempos, estabelecendo múltiplas relações a partir do seu meio social, mas com uma referência central nos grupos musicais e na sociabilidade que produzem. Nesse processo, é evidente como eles encontram poucos espaços nas instituições do mundo adulto para construir referências e valores por meio dos quais possam se construir com identidades positivas, colocar-se na cena pública como sujeitos, como cidadãos que são. A sociedade não lhes oferece muitas perspectivas. 0 mundo do trabalho lhes fecha as portas, a escola se mostra distante, não conseguindo entender nem responder às demandas que lhes são colocadas. Apesar de motivados e envolvidos com a música, não encontram estímulos e espaços para aprimorar o potencial criativo que demonstram, não existindo em Belo Horizonte uma política cultural que os contemple.
Nesse contexto o rap e o funk cumpriram e vêm cumprindo um papel significativo na vida desses jovens. Um primeiro aspecto diz respeito ao exercício da criatividade. Os estilos rap e funk possibilitam que esses jovens se introduzam na cena pública para além da figura do espectador passivo, colocando-se como criadores ativos, contra todos os limites de um contexto social que lhes nega a condição de criadores. Dessa forma, a experiência nos grupos musicais assume um valor em si, como exercício das potencialidades humanas. A música que criam, os shows que fazem, os eventos culturais dos quais participam aparecem como forma de afirmação pessoal, além do reconhecimento no meio em que vivem, contribuindo para o reforço da auto-estima. Ao mesmo tempo, através da produção cultural que realizam, principalmente o rape seu caráter de denúncia, colocam em pauta no debate público o lugar social do pobre e da pobreza.

Mas cada um dos estilos possui a sua especificidade. A melhor forma de caracterizálas é pelo duplo sentido que a palavra "diversão" oferece. Em um deles temos a diversão como ato ou efeito de distrair ou distrair-se: falta de atenção, abstração, irreflexão, esquecimento, divertimento (do latim, distractiond) . É o sentido do funk, no qual predominam as emoções, mediadas pela música. Podemos ver nele a expressão do direito legítimo dos jovens à alegria, à fruição, ao prazer. Poroutro lado, a diversão surge como um ato ou efeito de divergir: mudança de direção, desvio (do latim, diversiond. É o sentido do rap Mais do que o funk o estilo rapestimula o jovem a refletir sobre si mesmo, sobre seu lugar social, contribuindo para a ressignificação das identidades do jovem como pobre e negro. Ao mesmo tempo, ele cria uma forma própria de o jovem intervir na sociedade, por meio das suas práticas culturais. Mas não significa necessariamente que se coloque como uma forma de resistência ou mesmo como uma expressão política de oposição de classe. Prefiro ressaltar o seu sentido formativo, detectado numa pedagogia que parece gestar 
entre eles. Uma pedagogia da palavra, emitida pelas letras, por meio da qual não pretendem impor uma compreensão da realidade, mas "fazer o cara pensar", como nos disseram vários deles. Uma pedagogia na qual há o respeito pela diversidade, quando propõem que o outro, na sua condição de indivíduo, pense por si mesmo e tire suas próprias conclusões. Essa postura é coerente com as relações que estabelecem nos grupos, em que o coletivo não subsume o individual, o "nós" não abdica da condição do "eu".

Apesar dessas especificidades, podemos constatar significados comuns aos dois estilos. Um deles diz respeito à dimensão da escolha. 0 rap e o funkse colocam como um dos poucos meios pelos quais os jovens puderam exercer o direito às escolhas, elaborando modos de vida distintos e ampliando o leque das experiências vividas. Essa dimensão se torna mais importante quando levamos em conta que é o exercício da escolha, junto com a responsabilidade das decisões tomadas, uma das condições para a construção da autonomia. Se a escolha e a autonomia são frutos de aprendizagens, podemos nos indagar: Quais os espaços que esses jovens encontram no mundo adulto onde possam exercitar a prática de escolhas responsáveis, onde possam ir construindo-se como sujeitos autônomos?

Outra dimensão é a possibilidade que esses estilos proporcionam de vivência da condição juvenil. Para a maioria dos jovens pesquisados, os estilos funcionaram como um rito de passagem para a juventude, fornecendo-lhes elementos simbólicos, expressos na roupa, no visual ou na dança, para que pudessem construir uma identidade juvenil. Desde então, passaram a ser uma referência para a escolha dos amigos, bem como para as formas de ocupação do tempo livre, duas dimensões - o grupo de pares e o lazer - constitutivas da condição juvenil. A convivência continuada no grupo ou na dupla possibilitou a criação de relações de confiança e a aprendizagem de relações coletivas, servindo também de espelho para a construção de identidades individuais.

Todos enfatizam que a adesão aos estilos gerou uma ampliação dos circuitos e redes de trocas, evidenciando o rap e o funk como produtores de sociabilidades. A dinâmica das relações existentes, o exercício da razão comunicativa, a existência da confiança, a gratuidade das relações, sem outro sentido que não a própria relação, são aspectos que apontam para a centralidade da sociabilidade no processo de construção social desses jovens. Nesse sentido, os estilos podem ser vistos como respostas possíveis à despersonalização e à fragmentação do sistema social, possibilitando-lhes relações solidárias e a riqueza da descoberta e do encontro com os outros.

Podemos concluir constatando que o rap e o funk mesmo com abrangências diferenciadas, significaram uma referência na elaboração e vivência da condição juvenil, contribuindo de alguma forma para dar um sentido à vida de cada um, num contexto onde se vêem relegados a uma vida sem sentido. Ao mesmo tempo, o estilo de vida rap e funk possibilitou a muitos desses jovens uma ampliação significativa do campo de possibilidades, abrindo espaços para sonharem com outras alternativas de vida que não aquelas, restritas, oferecidas pela sociedade. Querem ser reconhecidos, querem uma visibilidade, querem ser alguém num contexto que os torna invisíveis, ninguém na multidão. Querem ter um lugar na cidade, usufruir dela, transformando o espaço urbano em um valor de uso. Enfim, querem ser jovens e cidadãos, com direito a viver plenamente a sua juventude. Este parece ser um aspecto central: pelos estilos rap e funk os jovens estão reivindicando o direito à juventude. 


\section{Referências bibliográficas}

ARCE, José ManueIValenzuela.Vida de barro duro cultura popular juvenil e grafite. Rio de Janeiro: Ed. UFRJ, 1999.

CASTEL, Robert.As armadilhas da exclusão 1995. (Mimeografado).

CHARLOT, Bernard.Da relação com o saber, elementos para uma teoria. Porto Alegre: Artemed, 2000.

DAYRELL, JuarezMúltiplos olhares sobre educação e cultura Belo Horizonte: Ed. UFMG, 1996. . Juventude, grupos de estilo e identidade.Educação em Revista,Belo Horizonte, n. 30, p. 25-39, dez. 1999.

. A música entra em cena: o rap e o funk na socialização da juventude em Belo Horizonte. São Paulo; 2001. Tese

(Doutorado em Educação) - Faculdade de Educação da Universidade de São Paulo.

DUBET, François.Sociologie de l'expérienceParis: Editions du Seuil, 1994.

;MARTUCELLI, Danilo.En la escuela.sociologia de la experiência escolar. Buenos Aires: Losada, 1997.

. A socialização e a formação escolar.Lua Novą São Paulo, n. 40/41, p. 241-266, 1997.

DURKHEIM, Émile.Educação e sociologia São Paulo: Melhoramentos, 1952.

HERSCHMANN, Micael.O funk e o hip hop invadem a cena Rio de Janeiro: Ed. da UFRJ, 2000.

. (Org.)Abalando os anos 90: funk e hip hop, globalização, violência e estilo cultura/Rio de Janeiro: Rocco, 1997

MANNHEIM, K. O problema sociológico das gerações. In: FORACHI, M.Mannheim.São Paulo: Ática, 1982.

MARTINS, José de Souza.Exclusão social e a nova desigualdade São Paulo: Paulus, 1997.

MELUCCI,A.Passagiod'epocail futuro è adesso. Milano: Feltrinelli, 1994.

I/ gioco dell'iqil cambiamento di sè in una società global. Milano: Feltrinelli,1996.

POCHMANN, Marcio Emprego e desemprego no Brasit as transformações nos anos 90. Campinas: Centro de Estudos Sindicais e de Economia do Trabalho (CESIT)/Unicamp, 1998. (Mimeografado).

SANSONE, Livio. Funk baiano: uma versão local de um fenômeno global? In: HERSCHMANN, Micael (Org).Abalando os anos 90 funke hip hop: globalização, violência e estilo cultural. Rio de Janeiro: Rocco, 1997.

SILVA, José Carlos Gomes.Rap na cidade de São Paulo música, etnicidade e experiência urbana. Campinas; 1998. Tese (Doutorado) - Departamento de Ciências Sociais, Instituto de Filosofia e Ciências Humanas da Universidade de Campinas.

SPOSITO, Marília P. A sociabilidade juvenil e a rua; novos conflitos e ação coletiva na cidade.TempoSocial,São Paulo, v.5, n. 1/ 2, p. 161-178, 1993.

Algumas hipóteses sobre as relações entre movimentos sociais, juventude e educação.Texto apresentado na ANPED, 1999 (Mimeografado).

TELLA, Marco Aurélio PazAtitude, arte, cultura e autoconhecimento o rap como voz da periferia. São Paulo; 2000. Dissertação (Mestrado) - Departamento de Ciências Sociais da Pontifícia Universidade Católica de São Paulo.

TELLES, Vera da Silva. A experiência da insegurança: trabalho e família nas classes trabalhadoras urbanas em São Paulo.Tempo Social,SãoPaulo, v.4. n. 1/2, p. 53-93, 1992.

TORTI, Maria Teresa.L'officina dei sogni,arte e vita nell'underground Genova: Costa e Nolan, 1994. 
VAN HAETCHT, AnneA escola à prova da sociologia Lisboa: Instituto Piaget, 1992

VIANNA, Hermano.O mundo funk carioca Rio de Janeiro: Jorge Zahar, 1987.

.(Org.)Galeras cariocaș territórios de conflitos e encontros culturais. Rio de Janeiro: Ed. da UFRJ, 1997.

Recebido em 25.02.2002

Aprovado em 03.05.2002

Juarez Tarcisio Dayrellé formado em Ciências Sociais pela UFMG. Tem vários artigos publicados além do livroMúltiplos olhares sobre educação e cultura pela Editora da UFMG. Atualmente é professor-adjunto na Faculdade de Educação da UFMG. 